\title{
Legal Culture of Modern Society: General Philosophical and Anthropological Analysis of the Category. Talking about the Structure of the Category.
}

\author{
Olga Miroshnichenko \\ ${ }^{1}$ Law School, Far Eastern Federal University, Vladivostok, Russia \\ Correspondence: Olga Miroshnichenko, Law School, Far Eastern Federal University, Vladivostok, Russia. E-mail: \\ olga-star.05@mail.ru
}

Received: April 9, 2014 Accepted: April 24, 2014 Online Published: May 26, 2014

doi:10.5539/ass.v10n12p1

URL: http://dx.doi.org/10.5539/ass.v10n12p1

\begin{abstract}
This article is talking about the structure of legal culture in the sense of philosophical and anthropological approach. General values of the society are presumed to be a basic, main part of legal culture; and legal values are supposed to be just modified common cultural values; thus, legal ideas are a form of common mindset rationalized with law. So, the author proposes to identify the basis of legal culture by eliciting predominant nucleus of common culture of the society.

The last part of the research contains the author's suggestions about an establishment of two-level structure of legal culture that should consist both of folk and state legal cultures. To understand the goal of this differentiation and combination we need to invoke etymology of the studied notion and remember that culture is a method of a nation's self-identification. The author suggests that only legal culture that comprises both of the stated blocks coexisting in harmony and complementing one another is a real mirror of legal life in any society. Observing and taking into consideration such legal culture, we can achieve the goals of the whole legal regulation: make almost all people who belong to the particular society understand and accept laws created by the public authority.
\end{abstract}

Keywords: culture, social culture, values, absolute values, traditional ideas, state and folk culture, moral culture, common mindset

\section{Introduction}

So, applying philosophical and anthropological approach allows us to state that the fundamental principle of the entire social regulatory system is the basic cultural model, called above the cultural dominant. Only later as the social and cultural reality gets more complex, the model takes a certain form of social standardization: either moral/religious obligation or mutual legal obligations. This way law and, for example, morality taken as cultural institutes of a certain society, differ in form but share part of the content determined by common cultural values, ideas and mindset.

Before continuing our discussions we need to find out how under this approach legal culture is different from other types of social culture, in particular, political and moral culture with which it is often compounded by representatives of classical theoretical paradigm.

\section{Discussion of the Topic}

As the conducted analysis showed there is a trend in research of the authors advocating different approaches to understanding legal culture: almost all of them come to defining values as its main conceptual characteristic. Thus the main question left to be answered is the notion of value.

Using the same philosophical and anthropological method we will try to prove that a legal value is only a type of common cultural values.

In fact, all regulators of social relations differentiated from the single cultural block at the initial stage; they are its specifically modified product at any stage of the society's development. Discussing connection between the law and common culture and importance of mental component of a given ethnos in such interworking, K.V. Aranovsky avers that the strength of legal postulation is often grounded in emotional intuitive understanding of legal reality rather than in its intellectual content. "... Scientific rationales that followed did not change much. 
The discovered connections of law to economic basis, practical public weal or struggle for survival do not shut off the clearly visible faith that was initially used as a basis for legal concepts".

In course of evolution of primitive society the single cultural block generated by human mind as a result of reflection is differentiated into the system of values. At the initial stage this system of values is just a set of stereotypes meant to make existence more convenient. The model and stereotypical behavior made life easier by eliminating the necessity to think about life circumstances. No doubt that at the initial stage this system of values varied depending on objective factors-geography, climate, economy; life circumstances that occurred in these societies varied as well. In this regard a man, being a reasonable creature, is prone to look for essence in everything; the essence was initially found in a myth, later in was found in religion. "Whatever the degree of deserialization of the world is, a man who chose secular life style cannot completely discard religious behavior... even most secular life keeps vestige of religious evaluation of the world".

At the current stage of social life the value component reflects mentality that is unique for every ethnos; this mentality is the "central zone" or "nucleus" of culture as Edward Shils put it. This nucleus is responsible for efficiency (or lack of it) of functioning of any social regulator. The mechanism is simple: concordance with the "nucleus of culture" makes a rule of conduct effective in any sphere of social relations; discordance makes it fictitious, not functioning. We deem that this value-based nucleus is the same for all regulators of social relations; this means, for law too. In other words, legal values are pre-determined by the type of culture and values commonly shared in it. Law, morality and religion as institutes of culture in a given society differ in form but share basic content that is determined by commonly shared cultural values, ideas and mindset.

Here we encounter notion of a value as a philosophical category introduced to define significance of certain phenomena resultant from reflection of the same by an individual. V.V. Ilyin states that "basic notion of value theory is a standard". Here we would like to emphasize that a standard is what is considered natural in a given society. It is not so called quasi-value that is blindly copied from a different society by naturalization and imposed forcibly; it is the typical, natural, traditional, standard cultural postulation of a specific society. In generic sense characteristics of a standard are expressed though two properties: regularity and standardization. Regularity is appropriateness of certain social relations (which is expressed though such properties as natural necessity, typical character, abundance, etc.) standardization of the social matter is its orderliness, establishment of standard models of relations, frameworks, scales, means of behavior. Standardization results from modeling function of standardized phenomena and is expressed though orderliness of social activities in the form of certain standards.

This means that basic value postulates that direct a given nation to a certain approach to life, to organizing life in a certain way, differ significantly from the same values of another nation. Thus the law manifests in different forms depending on what fundamental principle of civilization is emphasized as pivotal principle of a nation's social and legal organization.

The following appears intriguing in the present context: classically values are everything and only what inspires positive attitude, what is viewed as weal, good, beneficial, due. They are goals that people aspire to and are related to satisfying human needs. But what if people aspire to so-called "bad" values? Or is it true that what is negative in one society is absolutely positive in another society? For example, a polygamous marriage is a natural phenomenon for Muslim society, but is absolutely unacceptable for western European society. Here we should remember that values are predicated by culture and infer that "values are generated by historical experience and the most important proof of their credibility is public recognition". Philosophical aspect of the methodological approach that we proposed enables to elicit "material" absolute idea, basic cultural dominant that is unique for every society. This dominant enable the anthropological component of our methodology to identify new values corresponding to it on its basis. V.A. Rybakov states that "social memory is a backbone element of a man's living space", and "code of legal development is grounded in succession". Thus way the notion of "good" and "bad" depends on the type of culture and mindset of a given society, on its underlying dominant value, on the aforementioned nucleus of culture. Repeating words of S.B. Zinkovsky "values are most stable components of legal culture in any society; they reflect elements of its genetic code". Recognizing reception of most progressive ideas from other states as one of law development paths, we must not, nevertheless, underestimate this "genetic code". In our opinion functionality of the received standard is guaranteed by its concordance to the value component commonly shared in the culture. As Rene David stated "application and functioning of law depends on concept of social structure, type of civilization and mindset".

So, if we decide to consider legal culture a part of common culture, we presume that legal culture is subordinated to general laws of culture as a science. "Law begins with common values, mindset, etc., -writes Belgian 
professor Van Hook, -On the second stage law and legal practice create certain legal values, forms of mindset, traditions and habits, in other words, legal culture". The fundamental principle of the entire regulatory system is again cultural model, legal values are modified common cultural values; the legal ideas are a form of common mindset rationalized with law. This way we can identify basis of legal culture by eliciting predominant nucleus of common culture for each of the analyzed types.

This way as it was mentioned in previous part of our article, certain values lie in the bedrock of any type of culture. If we proceed on the stated premise on single origin of all types of culture, it becomes obvious that this origin is a kernel complied of "absolute" social and cultural values. American culture studies scholars A. Kroeber and K. Kluckhohn state that "basic kernel of culture is compiled of traditional (historically developed and approved) ideas. First of all these are the ideas that are vested with particular value. The difference is in so-called "specific" values-legal values for legal culture, political values for political culture, etc.

Here we return to the category of values, this time from the position of distinguishing between two types of them-absolute or ideal and relative or "second order" values. It is apparent that the values we call "absolute" will condition "second order" values-specific ones and make distinctions between various types of cultures. On the contrary, differentiating between various sub-types of cultures within one society is factored by specific values for each product of culture; these values develop in course of separation from the common cultural unit.

One of the goals of this article is to outline mechanism of shaping legal values or "second order" values. In our opinion attempts to change absolute values are fruitless. Here we are led to support opinion of V.P. Malakhov who states that values are "given elements of a culture that have no rational foundations. This way a value is identical to justifiability of living". "The only thing that can be stated about values, -says Russian jurist and philosopher, -and is that they exist; otherwise we can engage in intellectual speculations (ideology)-small talk... Values are not an object of legal theory since they cannot be elicited rationally as a consequence of something (factors, processes, laws, etc.). We can answer the question "why?" only by stating that objects of certain aspirations are considered values. In this phrase the word "value" adds nothing to the actual characteristics of the object of thoughts". This opinion is supported by famous American theoretician of law John Finnis who stated that "values cannot be proven, but can be supported both with observational evidence and with dialectical arguments. One day Blez Pascal called mechanism of absolute values operation "operation of heart", explaining that "logic of heart does not coincide with the logic of mind, but submits to its own inscrutable laws. As the French philosopher put it "values cannot be recognized by theoretical mind, but they can be felt".

I would like to make it clear that the aforementioned citations do not mean that fundamental social and cultural values do not change at all. It goes without saying that they do, otherwise cultural evolution would be impossible in principle. We are only trying to say here that attempts to "control" culture genesis in the "absolute" perspective are initially doomed; culture is not shaped or developed purposefully, it grows and builds up (accumulation, not modification). The "idea of a value is akin to ideas of a weal, good, right-everything that cannot be defined, but can be felt and accepted by virtue of spiritual affinity to it".

Basing on the aforementioned we suggest to define legal culture as two-level category with "absolute" values in its bedrock ("first order" values) that give ground for development of legal values ("second order values") that pertain exclusively to law as a given element of culture that regulates social relations within the framework of this culture. We think that endorsement of such a structure in the science will enable to develop an independent concept of identification within legal culture and define its criteria. Otherwise we might sink into the endless comparison of all legal cultures onto pseudo-ideal western model.

We propose as well to distinguish between two blocks within the legal culture: folk and state legal cultures. To understand the goal of this differentiation we need to invoke etymology of the studied notion and remember that culture is a method of a nation's self-identification. Saying this we mean exactly nation, not some mechanical group residing on a given territory. The main thing that motivates behavior in any realm of social relations, including the legal one, for each nation is an aggregate of absolute values that cannot be regulated rationally. A state tries to rationalize social life, plot main vectors and shape references for legal development. In worst case a state tries to "raise" level of legal culture with reference to the "ideal" one (western in the modern society). However, Russian experience known to all of us shows that if the existing "folk" legal culture does not concord with the imposed stereotype, the harder a state tries to push the country towards "bright new dawn", the stronger resistance from the population it encounters. Here we again cone round to the opinion of V.P. Malakhov who avers that "culture cannot be taken critically and be criticized since it is "deaf" to it. We can only create conditions for customary manifestations of culture and eliminate obstacles for them... Culture is a constitutional characteristic". 
In this sense a state is also a given element as well as its endless intention to rationalize, standardize and boost quality of legal life. In best case scenario such improvements will correspond to the common culture of the society, to its absolute values. In worse case so-called quasi-legal doctrines will develop: these are theories and concepts that exist in ideal state on the paper, but do not function in real life. Such phenomena have recently been widely discussed in legal science. As a rule true "folk" law is in this case called "non-law" or "pseudo-law", "shadow law". Most prominent positivists propose to use Hegel's formula of three types of "non-law" when comparing notions of official law with "negative law", "non-law", etc. In our opinion it is very categorical and this way is wrong. State legal ideology and state legal culture which shapes the former are intrinsic parts of the common legal culture equal to the folk legal culture. Theoretically true legal culture must comprise both of these spheres interworking in balance. Otherwise we are in danger of falling into the trap traditional for researchers of legal culture and start looking at this category only as at a given element. We should not forget that legal culture is first of all a form of common culture; correspondingly, its development is subordinated to the development of its main value-law. Saying law we mean both the law established by the state and the law originating from the national spirit. A famous Russian theoretician of law I.Yu. Kozlikhin distinguishes between two types of law genesis. "The first type is when the law is brought about by the social relations that require a legal form objectively and do not exist outside it. The second is when the law is created by will of the state. In the first case the resultant public order is spontaneous and natural. In the second case the public order is established artificially by means of state law". Professor I.Yu. Kozlikhin says that "ideally legal system comprises both of these parts interworking in balance. However in reality the law created by limited and often erroneous human mind poses danger for the spontaneously evolving law". The proposed structure combines both of these types this way matching the organics of law and rendering unnecessary artificial pseudo-scientific categories. It enables to research the natural pace of legal development in a given society.

\section{Conclusion}

This way we deem that only legal culture that comprises both of the stated blocks coexisting in harmony and complementing one another can become what it is meant to -"a logical result of the entire process of legal development naturally combining the two units one of which is brought about by the nature of a given society while the other is taken from legal culture of the past". In this case the state will be able to fulfill its function and as famous theoretician of law who worked before the revolution I.A. Ilyin said "bring the law closer to the people, strengthen the public legal consciousness, make people understand, know and appreciate the law, fulfill their obligations and observe restrictions at their free will and use their powers loyally". Otherwise if we diverge these given elements of social life towards opposite poles what we get is a "legal" society in the worst sense of this word. Under this scenario state legal culture exists in isolation not understood and not accepted by anyone besides those who established it while the folk legal culture stands against it. This situation brings about one of the most negative social phenomena-legal nihilism which can be avoided if we take the path of legal cultural evolution. Folk legal culture is a matrix that determines legal consciousness and behavior of citizens and members of the society in general. It shapes expectations and behavioral stereotypes as it pertains to situations of personal choice. That's why if official statutes contradict it the choice is not made in their favor". As V.P. Malakhov avers "taking reality as a reference to build on in shaping legal consciousness if reality itself is stimulated and constructed is a dead-end that is unfortunately well trodden".

\section{References}

Aranovsky, K. V. (2003). Constitutional tradition in the Russian environment (p. 39). Saint Petersburg. Legal Center Press Publishing House.

Bachinin, V. A. (2002). Non-law (negative law) as a category and social reality // State and law. 2001. No. 5: Samigullin V.K. Law and non-law // State and law. 2002. No. 3.

Baranov, V. M. (2005). "Shadow" law. N. Novgorod, 2002., Trikoz E.N. "Shadow" law: myth or reality // Legislation and economy. 2005. No. 1.

BixBr. (1996). Jurisprudence, 75. London.

Bocharov, V. V. (n. d.). Decree. Essays, 136.

David, R. (1988). Main legal systems of modern day, 38-40.

Gayvoronovskaya, Y. V. (2001). Concept of standard of law in national jurisprudence (p. 17). Dissertation summary. Dissertation of candidate of jurisprudence, Saint Petersburg.

Ilyin, I. A. (1993). On nature of legal consciousness, 31. 
Ilyin, V. V., \& Axiology, M. (2005). Publishing House of Moscow State University, 28.

Kozlikhin, I. Y. (2006). Law, legislation and power in the modern Russia (p. 66). Citations from: Our hard path to law: Materials of scientific and philosophical readings commemorating academician V.S. Nersesyants/Content by: V.G. Grafsky, M.: Norma.

Kroeber, A., \& Kluckhohn, C. (1952). Culture. A critical review of concepts and definitions (p. 173). Cambridge; Massachusetts.

Malakhov, A. V. (n. d.). Decree. Essays, 135-137.

Malakhov, V. P. (2013). Myths of contemporary general legal theory: Monography. In V. P. Malakhov (Ed.), Unity-Dana: Law and right (p. 101).

Malakhov, V. P. (n. d.). Myths of contemporary Russian legal reality, 22.

Martyshkin, O. V. (2004). Problem of values in theory of state and law. State and law, 6(10).

Mirch's eliade. (1994). Sacred and secular, 23(64).

Nenovsky, N. (1987). Law and values, 25(29).

Petruchak, L. A. (2002). Legal culture as a determinant of the contemporary Russian society, 1.

Rozanov, V. V. (n. d.). Pascal. Retrieved from http://vivovoco.rsl/VV/PAPERS/ECCE/PASCAL.HTM

Rybakov, V. A. (n. d.). Retrieved from http://rudocs.exdat.com/docs/index-403130.html?page=2

Van Hook, M. (n. d.). Decree. Essays, 82.

Zinkovsky, S. B. (2007). Legal cultures: Textbook, 80.

\section{Copyrights}

Copyright for this article is retained by the author(s), with first publication rights granted to the journal.

This is an open-access article distributed under the terms and conditions of the Creative Commons Attribution license (http://creativecommons.org/licenses/by/3.0/). 